\title{
Sickness in Salonica: my first, worst, and most successful clinical trial
}

\author{
A L COCHRANE
}

While acting as medical officer to "D" Battalion Layforce I was captured on Crete on 1 June 1941. Together with other prisoners I reached the transit camp for all prisoners of war at Salonica late in June, very tired and hungry. The camp was a run down overcrowded army barracks, infested with bed bugs. The diet was minimal-breakfast: unsweetened "ersatz" coffee; midday: a bowl of vegetable soup; evening: two slices of plain bread-in all, about 400 to 500 calories. We were always hungry.

At first there were few medical problems and sufficient medical officers. There was a 200 bedded building used as a hospital; I helped in outpatients. Then, in the course of one or two weeks, everything changed-particularly for me. Firstly, I was appointed chief medical officer by the Germans after a row in the hospital. I did not want the job, nor had I any qualifications for it. The only reason for the decision was that I spoke fluent German. I inherited the hospital with three drugs-aspirin, an inefficient skin disinfectant, and something said to stop diarrhoea. I discovered one great asset-a wonderful set of orderlies. They were from Australia, New Zealand, Yugoslavia, and the United Kingdom, but the backbone were the Quakers from the Friends Field Ambulance, captured in Greece.

Next came the evacuation of all the officers in the camp, leaving me with one medical assistant who took over the surgical cases. I thus became in addition senior British officer in charge of 8000 demoralised, hungry British prisoners of war. Both jobs were almost caricatures of responsibility without power. The third event was my diagnosis of the first case of diphtheria. This led to a serious epidemic of more than 80 cases. This was followed by a typhoid fever epidemic of about 12 cases. I was reasonably efficient at diagnosis. I had never previously seen a typhoid case, but the rose spots made it easy. The Germans refused all help with isolation, treatment, or screening, but there were only two deaths.

Towards the end of July came a lull. We were all exhausted, hungry, and depressed, but I had enough energy to organise a medical surveillance system of the camp. This was based on the lists of British prisoners kept for food ration distribution. Notes were made by a disabled Quaker who attended all outpatient clinics. The diagnoses recorded were sandfly fever, jaundice, malaria, enteritis, and "ankle oedema," of which a few men had complained.

\section{Increase in oedema}

August 1941 started fairly quietly with a mild epidemic of jaundice that made you itch, but decreased hunger. There was, however, a fairly rapid increase of oedema. The Germans then decided to attack our morale from a new angle shooting into the camp during daylight, mainly at the hospital and its staff. The first shot brought down the ceiling of a hospital room. The next went through my hair during a clinical round. The next wounded the arm of a New Zealand orderly who subsequently lost his arm. Then, increasing the tempo, two orderlies were shot, one of whom died. Finally, the Germans threw a hand grenade into a crowded barrack latrine. The result was indescribable. Medically, the

Barry, South Glamorgan

A L COCHRANE, MB, FRCP

Correspondence to: Rhoose Farm House, Rhoose, near Barry, South Glamorgan. position deteriorated rapidly. The jaundice epidemic increased, but more serious was the increase in oedema. After one week I had to change the level of diagnosis from "ankle oedema," to "oedema above the knee." The German doctors always claimed that the oedema was due to the sun and not to starvation. They apologised for the shooting but did nothing to stop it.

I became desperate. I was severely jaundiced and had pitting oedema above the knees. I argued in vain with the Germans. I decided that something must be done, and that I was the only one who could do it. I had a vague memory of the phrase "wet beriberi," so I decided to see if I could show that the oedema was due to a vitamin deficiency. That night I bought some yeast on the black market and the next morning I recruited 20 young prisoners.

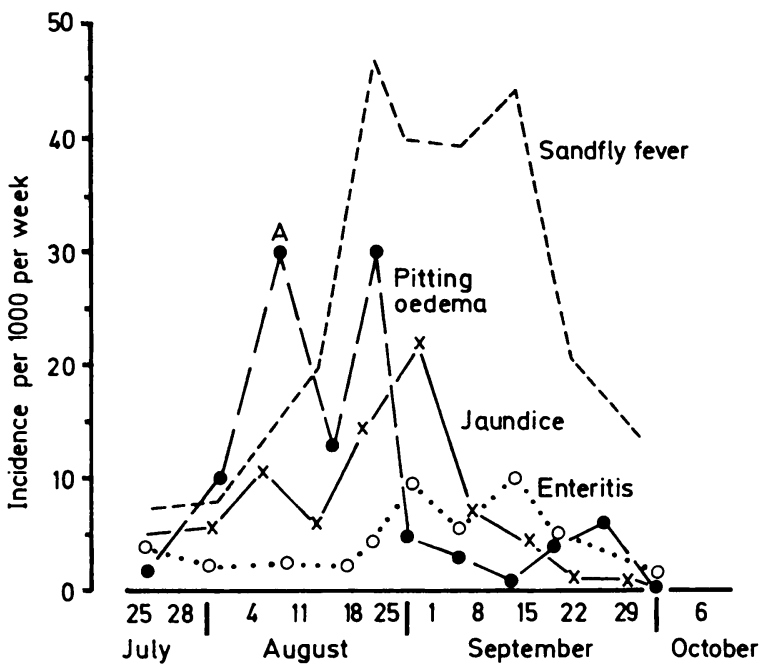

FIG 1-Incidence of morbidity for selected conditions in a prisoner of war camp in Salonica, 1941 .

$A=$ change of level of diagnosis for pitting oedema.

There seemed little wrong with them except emaciation above the waist and pitting oedema to above the knees. I gave them a short talk about my medical hero James Lind and they agreed to cooperate in an experiment. I cleared two wards. I numbered the 20 prisoners off: odd numbers to one ward and evens to the other. Each man in one ward received two spoonfuls of yeast daily. The others got one tablet of vitamin C from my "iron" reserve. The orderlies cooperated magnificently, despite the strain that they were under in running the hospital and this trial under frequent threat of being shot. They controlled fluid intake and measured frequency of urination. This last was the only outcome measure that I could think of, as we had no buckets to measure volume. There was no difference between the wards for the first two days, but the third day was hopeful, and on the fourth the difference was conclusive. I did two further but rather unsatisfactory tests. I asked the members of each ward whether they felt better, the same, or worse. Nine out of ten in the "yeast" ward felt better; none in the other. I also made them walk about for half an hour and then assessed the extent of the oedema. I convinced myself that there was less oedema in the "yeast" ward. I made careful notes of the trial and I immediately asked to see the Germans. Since I had become chief medical officer I had been making strong and frequent complaints, with minimal results, so I had little hope. I 
gave them a short talk, mentioning James Lind, then presented the results of my trial and argued that there was a major "epidemic" due to a diet deficient in vitamin B. I said that it was possibly wet beri-beri. I asked for a lot of yeast and more food. They said, as usual, that they would see what they could do.

I thought that I had played my last card and lost, but the unexpected happened, the Germans produced a lot of yeast. We

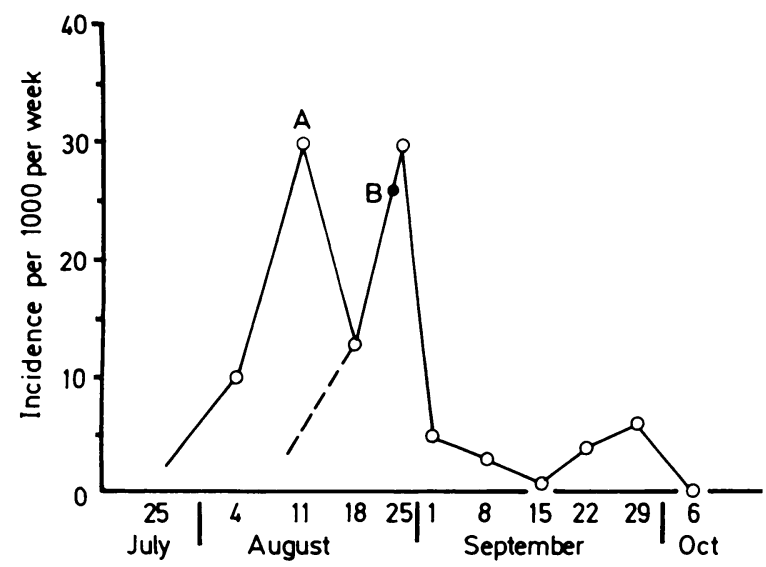

A Level of diagnosis is changed from oedema above ankle to oedema above knee

B Clinical trial

FIG 2-Probable increase and decrease of oedema. gave two teaspoonfuls a day to those with oedema above the knee, and one teaspoonful to those with ankle oedema. Figure 1 , which is copied from my original notes, shows the incidence. It is difficult to follow because of the change in the level of diagnosis from "ankle" oedema to oedema "above the knee" at point A. Figure 2 gives the probable rise and fall. As the oedema slowly disappeared (and the shooting stopped) morale in the camp improved. The fear of a major catastrophe passed and we began to relax. The camp was slowly evacuated, but a few survivors including myself remained until December 1941.

\section{A little bit of science, plus luck}

On reflection, it was not a good trial. I was testing the wrong hypothesis. The oedema was not wet beri-beri. Furthermore, the numbers were too small, the time too short, and the outcome measurements poor. Yet the treatment worked. I still do not know why. I imagine that the simplest explanation is that the small amount of protein in the yeast raised the plasma proteins sufficiently to correct fluid balance.

There are two additional points worth making. Firstly, it could be argued that the trial was randomised and controlled, although this last was somewhat inadequate. In those early days, when the randomised controlled trial was little known in medicine, this was something of an achievement. At the same time I can take little credit as the design of the trial was largely fortuitous. Secondly, the German doctor's remark, when I asked for more help, was "Ärtze sind überflüssing" ("doctors are superfluous"). This was probably correct, but it was amazing what a little bit of science and a little bit of luck achieved.

\title{
An unusual source of hospital wound infection
}

\author{
W A DICKSON, PAMELA BOOTHMAN, KAY HARE
}

The use of leeches in medical treatment is probably now regarded as of only historical interest, but they are, in fact, still widely used in plastic surgery to decongest flaps. ${ }^{12}$ Hirudo medicinalis-the medicinal leech-harbours bacteria, and Whitlock et al pointed out that it might be a source of infection. ${ }^{3}$ We present what we believe to be the first report of infection traced to this source.

\section{Case report}

A 27 year old white woman, para 3, who had had a left simple mastectomy for a stage I carcinoma of the breast two years previously was referred for reconstruction. On admission she was slim with an oblique mastectomy scar but no evidence of local, nodal, or metastatic disease. She had a moderate amount of redundant abdominal skin. There were no abdominal scars. A contralateral rectus abdominis flap was raised to reconstruct the left breast without using a prosthesis. ${ }^{4}$ Immediately after operation the flap was congested, but this improved spontaneously over the next few hours. On the first postoperative day, however, the flap became progressively more congested and a decision was made to apply leeches to it. They were attached regularly for four days and appeared to be effective

Plastic Surgery Unit, Canniesburn Hospital, Glasgow

W A DICKSON, FRCS, senior house officer in plastic surgery (present appointment: registrar in plastic surgery, St Luke's Hospital, Bradford)

Department of Bacteriology, Glasgow Royal Infirmary, Glasgow G4 OSF PAMELA BOOTHMAN, FIMLS, senior medical laboratory scientific officer KAY HARE, MD, DCP, consultant bacteriologist in reducing the congestion, except in an area on the superior aspect, which subsequently became necrotic (figure).

On the fifth postoperative day erythema of the flap and surrounding skin became apparent, and a course of cephradine was started. The erythema improved, and she was discharged on the ninth day. Three days later she returned with a haematoma, which was aspirated. Although there was no cellulitis at this time, within 24 hours she developed fever with signs of inflammation of the breast and a discharge of pus from the superior suture

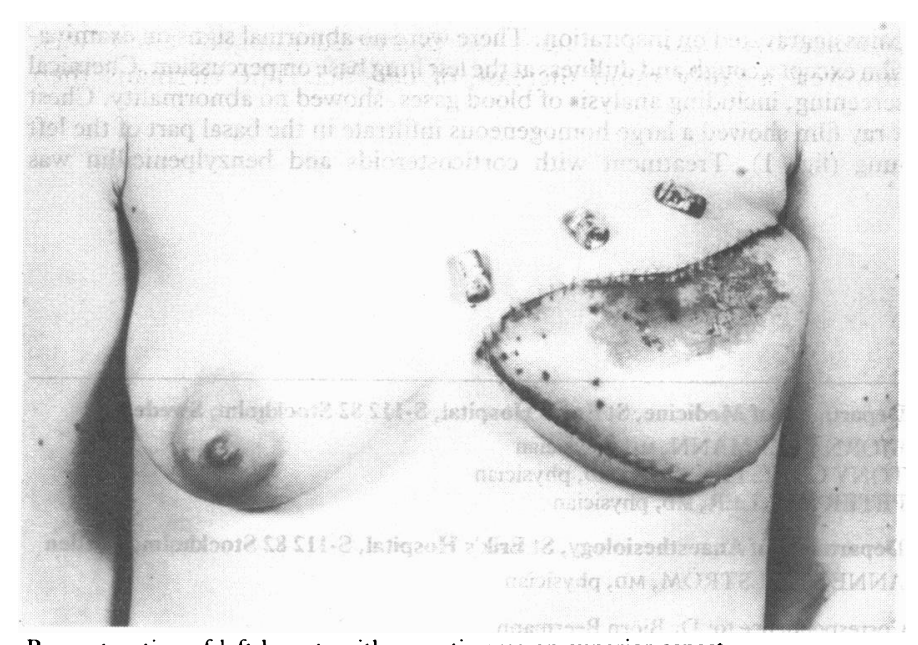

